\title{
The Customs Union Issue: Why do we Observe so few of them?
}

\author{
GIOVANNI FACCHINI \\ PERI SILVA \\ GERALD WILLMANN
}

CESIFO WORKING PAPER NO. 2426

CATEgORY 7: TRAde Policy

OCTOBER 2008

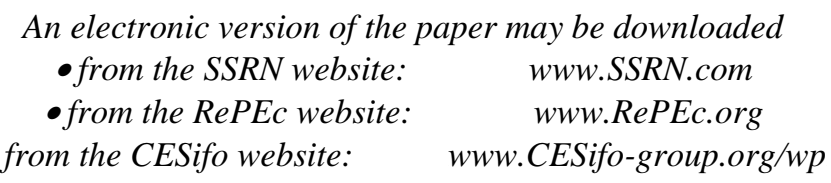




\title{
The Customs Union Issue: Why do we Observe so few of them?
}

\begin{abstract}
The number of preferential trade agreements has greatly increased over the past two decades, yet most existing bilateral arrangements take the form of free trade areas, and less than ten percent can be considered to be fully fledged customs unions. This paper develops a political economy model of trade policy under imperfect competition to provide a positive explanation for the prevalence of free trade areas. In a three-country setting, a representative from each prospective member is elected to determine the tariffs to be applied on imported goods. Under a customs union, the necessity to coordinate tariffs leads voters to strategically delegate power to more protectionist representatives. Contrary to most of the existing literature, we show that strategic delegation may imply that free trade areas increase welfare compared to customs unions. Moreover, the model also indicates that free trade areas are more likely to be politically viable than customs unions.
\end{abstract}

JEL Code: F10, F11, F13.

Keywords: strategic delegation, preferential trade agreements.

\author{
Giovanni Facchini \\ Department of Economics \\ University of Essex, Wivenhoe Park \\ UK - Colchester, Essex CO4 3SQ \\ gfacch@essex.ac.uk
}

\author{
Peri Silva \\ University of North Dakota \\ Gamble 290 L. Centennial Drive \\ USA - Grand Forks, ND 58202 \\ peri.dasilva@mail.business.und.edu
}

\author{
Gerald Willmann \\ Catholic University Leuven \\ Hogenheuvelcollege \\ Naamsestraat 69 \\ Belgium - 3000 Leuven \\ gerald.willmann@econ.kuleuven.be
}

October 1, 2008

Peri Silva acknowledges financial support from the College of Business and Public Administration at the University of North Dakota. The views expressed here are those of the authors and do not necessarily reflect those of the institutions with which they are affiliated. We would like to thank Cecilia Testa and participants at the 2008 Midwest International Economics meetings in Champaign and at the fourth Danish International Economics Workshop for useful comments. 


\section{Introduction}

In the last two decades the world economy has witnessed an impressive increase in the number of preferential trade agreements that entered into force. Interestingly, as reported by the World Trade Organization, ${ }^{1}$ ninety percent of the agreements in force as of April 2008 take the form of free trade areas or other limited scope agreements, while only ten percent are represented by customs unions (see Figure 1). Although these figures clearly indicate that free trade areas are more popular than customs unions, to the best of our knowledge the literature so far has not offered a systematic explanation for this stylized fact. The aim of this paper is to develop a political economy model of trade policy determination to explain the formation of preferential trade arrangements and to compare the social welfare effects and political viability of free trade areas (FTAs) and customs unions (CUs).

A large literature has studied the effects of the formation of preferential trade agreements. In particular, several recent contributions have focused on the comparison of social welfare under a free trade area and a customs union. Ornelas (2007) uses an oligopolistic competition model to show that customs unions raise social welfare relative to free trade areas in member countries. He is also able to show that the existence of a customs union can be thought of as a building block towards global free trade, as it decreases the status quo welfare of nonmembers, and thus makes the global free trade option more attractive for them. Saggi (2006) uses a similar setup to show once again that customs unions raise social welfare relative to free trade areas in member countries. Differently from Ornelas (2007), using a repeated game framework, he concludes that customs unions and free trade areas can be thought of as stumbling blocs for multilateral liberalization. Interestingly, this result arises because in an FTA the non-members willingness to cooperate on multilateral tariff liberalization declines, while in a CU members are less willing to cooperate. Notice that trade policies in both Ornelas (2007) and Saggi (2006) are chosen to maximize social welfare.

Other papers investigate the political viability of free trade areas. Grossman and Helpman (1995) and Krishna (1998) show that welfare reducing free trade areas are politically viable in economic settings where pressure groups are important determinants of the free trade

\footnotetext{
${ }^{1}$ See: http : //www.wto.org/english/tratop_e/region_e/region_e.htm.
} 


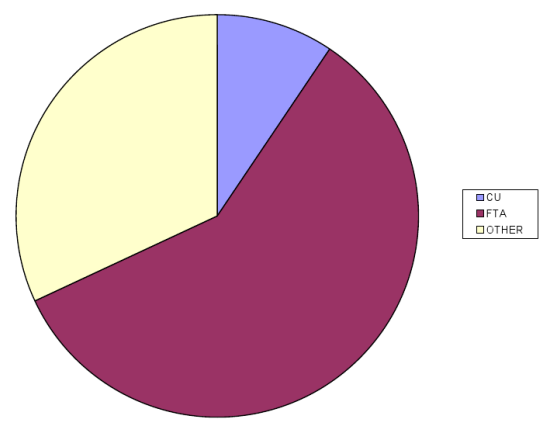

Figure 1: Preferential Trading Arrangements by type (April 2008)

area formation process. Key to these results is the assumption that tariffs on non-member countries are frozen at the pre-formation levels. On the contrary, Ornelas (2005a) shows that if post-formation external tariffs are endogenously determined, then the political viability of welfare reducing free trade areas is critically undermined even in the presence of pressure groups. In this case, he shows that the government may end up not endorsing welfare enhancing free trade areas but, at the same time, cannot endorse welfare reducing ones when pressure groups do not influence the government's decision to create a free trade area. ${ }^{2}$

To analyze the political desirability of a free trade area and of a customs union, we develop a simple three-country model, in which two potential members strategically interact to choose the tariff levels to be implemented vis à vis each other and the rest of the world, whereas the rest of the world implements most-favored-nation tariffs. The underlying oligopolistic economic structure has been used in several analyses of regionalism (Ornelas 2005b, Ornelas 2007, Freund 2000 and Krishna 1998 among others) and in particular it allows countries which are 'small' from the point of view of world income, to influence their import prices because markets are segmented and firms are price setters. Importantly, in this setting, it is impossible for a country to benefit directly from the reduction in tariffs towards

\footnotetext{
${ }^{2}$ Facchini and Testa (2008) investigate the political economy of the formation of common markets. They conclude that politically viable common markets must enhance the protection received by some factors of production. Thus, they argue that there exists an intrinsic tension between social desirability and market integration.
} 
the partner country brought about by the agreement. At the same time, a country can be made better off by allowing the partner's exporters to enjoy the gains from (distortionary) trade diversion in its own market if the preferential access granted to the partner is the result of preferential access received from the partner.

Building upon this structure, in order to model the choice of a preferential trading arrangement, we consider a representative democracy framework in which the policy maker is chosen in each country among all citizens, and the elected representative is unable to commit ex-ante to a given policy. This approach has been previously used by Laussel and Riezman (2005) and Willmann (2005) to analyze the endogenous formation of trade policy, and has allowed to highlight the important role played by strategic delegation in shaping policy outcomes. ${ }^{3}$ Our analysis shows that strategic delegation is also key to understanding the likelihood of two countries forming a preferential agreement, and of the nature of the agreement that will emerge in equilibrium. Although the focus of our analysis is on delegation within a country in the presence of heterogeneous agents, in an early contribution Gatsios and Karp (1991) have considered the role of strategic delegation between countries within a customs union. In particular, they have shown that in a setting where the rest of the world acts strategically, one member country may want to delegate to the other member country the authority to set the common external tariff of the customs union, depending on whether the policies followed by member and non member countries are strategic complements or substitutes.

To carry out our analysis we consider a four-stage game. In the first stage, each potential member country holds a sequence of referenda to decide whether a non-discriminatory MFN trade policy, a free trade area or a customs union will be implemented. In the second stage, voters in each country elect a representative who will choose the tariff level vis à vis the rest of the world in the third stage of the game. The emerging trade policy is non-discriminatory under the MFN regime, while free trade will instead prevail between

\footnotetext{
${ }^{3}$ This idea has been applied in a variety of other contexts. For instance, Schelling (1956) has pointed out the potential gains for a principal to delegate decision making power to an agent who is "tougher" than himself. Jones (1989) and Segendorff (1998) have formalized this idea in a general bargaining setting. Conconi, Facchini and Zanardi (2008) have applied it to analyze the working of fast track authority in the US congress.
} 
members of the preferential trade agreement with or without coordination of the external tariffs depending on the nature of the agreement. In the fourth stage, firms compete in quantities, taking as given the trade policy that has been set during the third stage.

Ownership of the oligopolistic firm is unevenly distributed among the citizenry, and in our setting the individual with the median ownership share turns out to be the pivotal player. Assuming that the median voter receives a fraction of the profits that is lower than the fraction accrued to the average citizen, we are able to relate the distribution of income in a particular country to the choice of trade regime. Notice that in our model a representative cannot commit to choose a tariff level that differs from his most preferred one. Thus, in general, representatives will choose tariffs that do not necessarily maximize social welfare, and the median voter will take this into account in selecting the country's representative.

The supply side of the model presents geographically specialized production patterns, since each prospective member country produces different subsets of final goods. This assumption allows us to establish several interesting results. In particular, we find that the necessity to coordinate tariffs in customs unions leads voters to strategically delegate power to more protectionist representatives. This result is not true for free trade area formation. In contrast to the literature, we are also able to show that strategic delegation may lead to a situation in which free trade areas raise welfare relative to customs unions if the degree of income inequality is sufficiently small. Moreover, in our model, free trade areas raise welfare relative to the MFN regime independently of the distribution of income, while customs unions decrease welfare relative to the MFN regime if the degree of income inequality is sufficiently small.

We also investigate the political viability of preferential trade agreements. In the first stage of the game, each prospective member country holds a sequence of referenda to decide whether a free trade area, a customs union or a non-discriminatory MFN policy will be implemented. The political viability of preferential agreements depends on how they affect the median voter's indirect utility function. Since the median voter receives a share of profits lower than the average share of profits distributed in society, profits derived from high tariffs are less important for political viability than for social welfare. We conclude that customs 
unions are not politically viable independently of the distribution of income, while free trade areas are politically viable if income inequality is sufficiently low. Moreover, the results indicate that only welfare-enhancing free trade areas are politically viable. These results are robust to the introduction of asymmetries in the size of the market in the non-member country, as well as to differences in the distribution of income across member countries.

The rest of the paper is organized as follows. In section 2 we introduce the model and determine the equilibrium prices and quantities taking as given the tariff levels implemented by each country. In Section 3 we determine the equilibrium tariff levels under different trade policy regimes, and compare the social welfare effects of the different preferential trade agreements. In Section 4 we examine the political viability of the different preferential trade arrangements, while in section 5 we extend our analysis by introducing asymmetries in the size of member and non member countries, as well as in the income distribution across countries. Section 6 concludes.

\section{The Model}

To analyze the formation of a preferential trade agreement, we employ a standard oligopolistic trade model that has been used in several analyses of regionalism (Ornelas 2005b, Ornelas 2007, Freund 2000 and Krishna 1998). In particular, we consider a threecountry, three-good setting, where country $A$ and $B$ are prospective members, while country $F$ is an aggregate entity that stands for the rest of the world. Good 0 is a basic good that is produced in all three countries, using only labor according to the identity production technology $X_{0}=L_{0}$. This good is freely traded and serves as the numéraire. As a result, if this good is produced in equilibrium, wages will be equal to 1 . Goods 1 and 2 are instead produced by duopolies with one firm being located in country $F$, and the second in member country $A(\operatorname{good} 1)$ and member country $B(\operatorname{good} 2)$ respectively. ${ }^{4}$ The two goods are produced using labor and a sector specific input according to a constant returns to scale production function, which gives rise to a constant marginal cost of production $c$ (in terms

\footnotetext{
${ }^{4}$ We will relax this assumption in section 5 .
} 
of the numéraire). Oligopolistic firms compete in quantities (Cournot competition).

Introducing notation that will prove useful later on, let $x_{s, d}^{i}$ denote the quantity of good $i$ produced in country $s$ and consumed in country $d$. Our geographically specialized production pattern implies that $x_{B, d}^{1}=x_{A, d}^{2}=0$. Each country can apply tariffs on trade with its partners unless a preferential trade agreement is in place. ${ }^{5}$ Denote by $t_{s, d}$ the tariff applied by country $d$ in $\{F, A, B\}$ on imports from country $s$ in $\{F, A, B\}$, where clearly $t_{d, d}=0$. Country $d$ 's tariff matrix is described by $\mathbf{t}_{d}=\left(t_{A, d}, t_{B, d}, t_{F, d}\right)$. The tariffs applied by the various countries can be denoted more synthetically in matrix form by $\mathbf{t}=\left(\mathbf{t}_{F}, \mathbf{t}_{A}, \mathbf{t}_{B}\right)$ where the tariff on products traded between PTA members is zero, as are the elements on the diagonal.

The population in each country consists of a continuum of individuals of mass one. Each individual supplies one unit of labor, but individuals differ in the stake they own in the specific factor employed by the profitable duopolists. We denote by $\gamma_{s, l}$ the fraction of the oligopolistic sector's profits allocated to individual $l$ in country $s$. We assume that the oligopolistic sector's distribution of profits is the same in countries $A$ and $B$. Without loss of generality, we index individuals in ascending order, and normalize the fraction of the profit that is received by the average voter to one $(\bar{\gamma}=1)$. Typical wealth distributions then imply that $\gamma^{m} \leqslant 1$ (Alesina and Rodrik 1994). Following Dutt and Mitra (2002), $\gamma^{m}$ can be considered an inverse index of inequality - or an index of equality in the distribution of assets.

Preferences are identical across countries and individuals and can be described by the following quasi-linear, additively separable, utility function:

$$
u(x)=x^{0}+\sum_{i} u_{i}\left(x^{i}\right)
$$

where $u_{i}()=.H x^{i}-\frac{x^{i^{2}}}{2}$, implying that the demand for goods 1 and 2 are linear and take the form $x^{i}=H-p^{i}$. The assumptions used on the supply side and demand side of the model

\footnotetext{
${ }^{5}$ If a preferential trade agreement is in place and member countries' external tariffs are different, then we assume that rules of origin are applied to prevent the duty free trans-shipment of goods between countries $A$ and $B$.
} 
imply that markets for goods 1 and 2 are segmented, i.e. prices in country $s$ are not affected by tariffs imposed by country $d$.

Given the above utility function, the indirect utility of individual $l$ in country $s$ can be written as follows:

$$
v\left(\mathbf{t}, \gamma_{s, l}\right)=1+\gamma_{s, l}^{i} \pi_{s}^{i}(\mathbf{t})+\sum_{d} \sum_{i} t_{d, s}^{i} x_{d, s}^{i}\left(\mathbf{t}_{s}\right)+\sum_{i}\left[u\left(x^{i}\left(\mathbf{t}_{s}\right)\right)-p_{s}^{i}\left(\mathbf{t}_{s}\right) x_{s}^{i}\left(\mathbf{t}_{s}\right)\right]
$$

where the first term represents labor income and the second the share of profits of sector $i, \pi_{s}^{i}(\mathbf{t})=\sum_{d}\left[p_{d}^{i}-c-t_{s, d}^{i}\right] x_{s, d}^{i}$, allocated to individual $s$ in country $l$. The third term captures tariff revenues which are lump sum rebated to each individual, and the fourth describes instead consumer surplus.

We consider a four stage game among the three countries where different trade policy regimes can be chosen by country A and B. In the first stage, each perspective member holds a sequence of referenda to choose between a non-discriminatory "most-favored-nation" trade policy, a free trade area or a customs union. In the second stage, the population of each country elects a representative who will, in the third stage, decide the countries' tariff policy. If no preferential agreement is in place, each country's representative will choose the non discriminatory tariffs to be applied on all trade. If a preferential agreement is in place, then the representatives of countries $A$ and $B$ decide tariffs on country $F$. In this case, the formation of a free trade area does not require cooperation between elected representatives to decide tariffs on country $F$, whereas we follow the literature in assuming that the formation of a customs union does. In stage four, firms compete in quantities, taking as given the trade policy that has been set during the third stage. We solve the model by backward induction, starting at stage four.

\subsection{Fourth Stage: Production and Consumption Choices}

In the fourth stage of the model, firms make production choices taking as given the tariff matrix t. If a preferential agreement between countries $A$ and $B$ is in place, then $t_{A B}^{i}=t_{B A}^{i}=0$ for all $i$. Otherwise, countries apply MFN tariffs on imports. Notice that 
country $F$ always applies MFN tariffs on goods imported from countries $A$ and $B$. The application of a MFN tariff on goods imported from countries $A$ and $B$ does not affect the equilibrium in these two countries, since markets are segmented in this model. Thus, country F's trade policy does not change throughout the analysis. This allows us to focus on the equilibrium outcomes in countries $A$ and $B$.

In general terms, country $s$ firm producing good $i$ solves the following problem with respect to country d's market:

$$
\max _{x_{s, d}^{i}}\left[p_{d}^{i}-c-t_{s, d}^{i}\right] x_{s, d}^{i}
$$

where to save on notation we have omitted the fact that quantities and prices are a function of the tariffs. The first order condition is given by

$$
\frac{\partial p_{d}^{i}}{\partial x_{s, d}^{i}} x_{s, d}^{i}+p_{d}^{i}=c+t_{s, d}^{i} \quad \text { for all } d
$$

Focusing on country $A$ (a similar analysis applies to $B$ ) and using our assumption of linear demand, equation (3) implies that

$$
\begin{aligned}
& x_{A, A}^{1}-x_{F, A}^{1}=t_{F, A}^{1} \\
& x_{B, A}^{2}-x_{F, A}^{2}=t_{F, A}^{2}-t_{B, A}^{2}
\end{aligned}
$$

Thus, a firm's sales in country $A$ differ from its competitors' sales according to the difference in the tariffs imposed on imports. Rearranging, we obtain the following equilibrium prices and quantities

$$
\begin{aligned}
x_{A, A}^{1}=\frac{\left(H+t_{F, A}^{1}-c\right)}{3} & x_{B, A}^{2}=\frac{\left(H+t_{F, A}^{2}-2 t_{B, A}^{2}-c\right)}{3} \\
x_{F, A}^{1}=\frac{\left(H-2 t_{F, A}^{1}-c\right)}{3} & x_{F, A}^{2}=\frac{\left(H+t_{B, A}^{2}-2 t_{F, A}^{2}-c\right)}{3} \\
p_{A}^{1}=\frac{\left(H+t_{F, A}^{1}+2 c\right)}{3} & p_{A}^{2}=\frac{\left(H+t_{F, A}^{2}+t_{B, A}^{2}+2 c\right)}{3}
\end{aligned}
$$

where we assume that $H>c$. As is clear from expressions (5), the price of good 1 and 2 in 
$A$ depends only on the trade policies adopted by that country and does not depend instead on the trade policy adopted by any other country, i.e. markets are segmented.

\section{Second and Third Stages: Determining Tariff Policy}

In this section we determine the trade policy chosen by the elected representatives of the two prospective member countries, and the identity of the representative. We consider different scenarios with respect to trade policy determination. We start by analyzing the non-cooperative scenarios (MFN and FTA) in which country A and B set non-cooperatively their policy vis à vis the rest of the world and compare the resulting levels of protection. We turn next to the analysis of the cooperative outcome $(\mathrm{CU})$ and compare then welfare across the different trade policy regimes.

\subsection{Non-cooperative trade policies}

Our representative democracy framework calls for the population of each country to elect a citizen who will choose the tariff level to be applied on imports from other countries. The objective of each representative is then to find tariffs that maximize his own welfare, given the tariffs chosen by other countries. We represent the share of the representative's profit by using 'hats' and continue focusing our analysis on country $A$. The representative's problem is given by:

$$
\max _{t_{A}} v\left(\mathbf{t}, \widehat{\gamma}_{A}\right)
$$

where the indirect utility function is described in (2). The difference between the MFN and the FTA regimes is that in the former the tariffs applied on imports do not depend on the good's country of origin, while if A is part of an FTA with B, imports from B are allowed to enter free of duty. Assuming that an interior solution exists ${ }^{6}$, the tariff vector chosen by representative $\hat{\gamma}_{A}$ is given by

$$
\mathbf{t}_{A}=\mathbf{t}_{A}\left(\hat{\gamma}_{A}, \hat{\gamma}_{B}\right)
$$

\footnotetext{
${ }^{6}$ See Helpman (1997) for details.
} 
in other words, the tariff vector chosen by the representative in country A depends on his identity and potentially also on the identity of the other country's representative. Who will serve as the country's representative in the determination of trade policies? Our hypothesis allows us to invoke the median voter theorem to answer this question. in particular, the median voter's second stage problem is given by:

$$
\max _{\widehat{\gamma}_{A}} v\left(\mathbf{t}\left(\widehat{\gamma}_{A}, \widehat{\gamma}_{B}\right), \gamma_{A}^{m}\right)
$$

We are now ready to establish our first result:

Lemma 1 If trade policies are set non-cooperatively, strategic delegation does not arise in equilibrium. Furthermore, if an FTA is formed, tariffs applied to non member countries are (weakly) lower than under a MFN arrangement.

Proof. Focusing on country A, we start by solving, for a given representative $\hat{\gamma}_{A}$, the MFN tariff determination problem. The first order conditions for problem 6 can be written as follows:

$$
\begin{aligned}
-\frac{\partial p_{A}^{1}}{\partial t_{A}^{1}} x_{A}^{1}+x_{F, A}^{1}+t_{A}^{1} \frac{\partial x_{F, A}^{1}}{\partial t_{A}^{1}}+\widehat{\gamma}_{A} \frac{\partial \pi_{A, A}^{1}}{\partial t_{A}^{1}}=0 \\
-\frac{\partial p_{A}^{2}}{\partial t_{A}^{2}} x_{A}^{2}+x_{A}^{2}+t_{A}^{2}\left(\frac{\partial x_{F, A}^{2}}{\partial t_{A}^{2}}+\frac{\partial x_{B, A}^{2}}{\partial t_{A}^{2}}\right)=0
\end{aligned}
$$

where we used the fact that $x_{B, A}^{1}=x_{A, A}^{2}=0$. Using the equilibrium price and quantities described in (5) we obtain the following equilibrium tariffs

$$
\begin{aligned}
t_{A}^{M F N, 1} & =\frac{(H-c)\left(1+2 \widehat{\gamma}_{A}\right)}{11-2 \widehat{\gamma}_{A}} \\
t_{A}^{M F N, 2} & =\frac{(H-c)}{4}
\end{aligned}
$$

From (10) it is clear that the choice of tariff in country $A$ does not depend on the identity of country B's representative.

Turning now to the choice of the country's representative under a MFN policy, the first 
order condition of problem (8) is given by:

$$
\underbrace{\sum_{i} \frac{\partial v\left(\mathbf{t}^{M F N}\left(\widehat{\gamma}_{A}, \widehat{\gamma}_{B}\right), \gamma_{A}^{m}\right)}{\partial t_{A}^{M F N, i}} \frac{\partial t_{A}^{M F N, i}}{\partial \widehat{\gamma}_{A}}}_{\text {Term 1 }}+\underbrace{\sum_{i} \frac{\partial v\left(\mathbf{t}^{M F N}\left(\widehat{\gamma}_{A}, \widehat{\gamma}_{B}\right), \gamma_{A}^{m}\right)}{\partial t_{B}^{M F N, i}} \frac{\partial t_{B}^{M F N, i}}{\partial \widehat{\gamma}_{A}}}_{\text {Term 2 }}=0
$$

where from equation (10) we know that Term 2 is equal to zero since $\frac{\partial t_{B}^{M F N, i}}{\partial \widehat{\gamma}_{A}}=0$. Moreover, equation (10) also imply that $\frac{\partial t_{A}^{M F N, 1}}{\partial \widehat{\gamma}_{A}}>0$ and $\frac{\partial t_{A}^{M F N, 2}}{\partial \widehat{\gamma}_{A}}=0$ so that equation (11) can be re-written as $\frac{\partial v\left(\mathbf{t}^{M F N}\left(\widehat{\gamma}_{A}, \widehat{\gamma}_{B}\right), \gamma_{A}^{m}\right)}{\partial t_{A}^{M F N, 1}}=0$. Thus we have that

$$
\left(\frac{H+t_{A}^{M F N, 1}-c}{3}\right)\left(1+2 \gamma_{A}^{m}\right)-4 t_{A}^{M F N, 1}=0
$$

We can substitute $t_{A}^{M F N, 1}$ as described in (10) which yields

$$
\widehat{\gamma}_{A}=\gamma_{A}^{m}
$$

In other words, the median voter in each country does not delegate power. The equilibrium MFN tariffs are then expressed by

$$
\begin{aligned}
t_{A}^{M F N, 1} & =\frac{(H-c)\left(1+2 \gamma^{m}\right)}{11-2 \gamma^{m}} \\
t_{A}^{M F N, 2} & =\frac{(H-c)}{4}
\end{aligned}
$$

and similar expressions apply to country $B$. Thus, our geographically specialized production pattern implies that $t_{A}^{M F N, 1}=t_{B}^{M F N, 2}$ and $t_{A}^{M F N, 2}=t_{B}^{M F N, 1}$ in equilibrium.

Turning now to the analysis of the FTA, the solution of problem 6 is given by

$$
\begin{aligned}
t_{F, A}^{F T A, 1} & =\frac{(H-c)\left(2 \widehat{\gamma}_{A}+1\right)}{\left(11-2 \widehat{\gamma}_{A}\right)} \\
t_{F, A}^{F T A, 2} & =\frac{(H-c)}{11}
\end{aligned}
$$

and similar expressions apply to country $B$. We turn next to the identification of each mem- 
ber country's representative under an FTA. Following the expressions in (13) and applying the same rationale applied to the MFN case, it is straightforward to show that

$$
\widehat{\gamma}_{A}=\gamma_{A}^{m}
$$

Thus, once again the median voter in each country does not delegate power. The equilibrium tariffs are then given by

$$
\begin{aligned}
t_{F, A}^{F T A, 1} & =\frac{(H-c)\left(1+2 \gamma^{m}\right)}{\left(11-2 \gamma^{m}\right)} \\
t_{F, A}^{F T A, 2} & =\frac{(H-c)}{11}
\end{aligned}
$$

Similarly, we can solve country $B$ 's median voter problem and show that $t_{F, A}^{F T A, 1}=t_{F, B}^{F T A, 2}$ and $t_{F, A}^{F T A, 2}=t_{F, B}^{F T A, 1}$. Comparing equation 14 and 12 thus immediately establishes the second part of the result.

For future reference, note that the tariff applied on imports of good 1 is increasing in $\gamma^{m}$ in the MFN and FTA situations. This implies that the tariff on imports of good 1 decreases in the extent of inequality. This is because less inequality means that the median owns a higher share of the domestic firm and hence has more interest in a higher tariff.

The intuition for the first part of the lemma 1 is as follows. In our model, markets for goods 1 and 2 are segmented, and as a result the equilibrium prices in country $A$ bare no relationship to the equilibrium prices in country $B$. Moreover, in this non-cooperative setting, tariffs applied by country $A$ can differ from the tariffs applied by country $B$. Clearly, the median voter does better by simply representing her own interests, because she has no influence on the partner's decision in this case.

As for the second part of the lemma 1, the decline in the tariff applied to the nonproduced good in the FTA compared to the MFN is related to the distortionary effects generated by the preferential access granted to the partner country. In other words, the median voter is able to attenuate the degree of trade diversion generated by the preferential access granted to the partner country by lowering the external tariff when moving from the MFN situation to the FTA situation. This is what is known in the literature as "the tariff 
complementarity effect" (Ornelas 2007). ${ }^{7}$ Finally, notice that the effect of trade policy on the partner's firm is not internalized in the non-cooperative solution. We turn next to the study of cooperative preferential agreements.

\subsection{Cooperative trade policies}

The main feature of customs unions is that member countries coordinate their external trade policies and apply common external tariffs. In this case, we follow most of the literature $^{8}$ by interpreting tariff coordination in customs union as a cooperative solution to the choice of member countries' common external tariffs. Following this line of argument, the choice of external tariffs is the solution to the following problem

$$
\max _{t^{i}} v\left(\mathbf{t}, \widehat{\gamma}_{A}\right)+v\left(\mathbf{t}, \widehat{\gamma}_{B}\right) \quad \text { for } i=\{1,2\}
$$

where $\hat{\gamma}_{A}$ and $\hat{\gamma}_{B}$ are the elected representatives in the two countries and now tariffs applied on trade with country $F$ are equal $\left(t^{i}=t_{F, A}^{i}=t_{F, B}^{i}\right)$ across countries, but not necessarily across sectors. The resulting tariff vector chosen is given by

$$
\mathbf{t}^{C U}=\mathbf{t}^{C U}\left(\hat{\gamma}_{A}, \hat{\gamma}_{B}\right)
$$

As before, in the second stage of the model, the representatives will be chosen by the median voter as the solution to the following problem

$$
\max _{\widehat{\gamma}_{A}} v\left(\mathbf{t}^{C U}\left(\widehat{\gamma}_{A}, \widehat{\gamma}_{B}\right), \gamma_{A}^{m}\right)
$$

We are then able to establish our second result

\footnotetext{
${ }^{7}$ Estevadeordal, Freund and Ornelas (2008) find strong support for the presence of this effect in their empirical study of preferential trading arrangements in Latin America.

${ }^{8}$ Ornelas (2007) and Saggi (2006) model the choice of common external tariffs to maximize the aggregate welfare of the countries. In this case, the representative voter would correspond to the average voter in our paper. In a model with strategic delegation,Willmann (2005) assumes that legislators maximize their aggregate welfare when choosing the most-favored-nation tariffs for a small economy. Similarly, Grossman and Helpman (2005) assume that the legislative majority maximizes its aggregate welfare when choosing most-favored-nation tariffs for a small economy.
} 
Lemma 2 If trade policy is set cooperatively, strategic delegation occurs, and the elected representative is an individual with an ownership share in the import competing firm twice that of the median voter.

Proof. The first order conditions of problem (15) are given by

$$
\begin{aligned}
&-\frac{\partial p_{A}^{1}}{\partial t^{1}} x_{A}^{1}+x_{F, A}^{1}+t^{1} \frac{\partial x_{F, A}^{1}}{\partial t^{1}}+\widehat{\gamma}_{A} \frac{\partial \pi_{A, A}^{1}}{\partial t^{1}}=0 \\
&-\frac{\partial p_{A}^{2}}{\partial t^{2}} x_{A}^{2}+x_{F, A}^{2}+t^{2} \frac{\partial x_{F, A}^{2}}{\partial t^{2}}+\widehat{\gamma}_{B} \frac{\partial \pi_{B, B}^{2}}{\partial t^{2}}=0
\end{aligned}
$$

where symmetry implies that $x_{A}^{1}=x_{B}^{1}, x_{A}^{2}=x_{B}^{2}, \pi_{A, A}^{1}=\pi_{A, B}^{1}$, and $\pi_{B, A}^{2}=\pi_{B, B}^{2}$ in equilibrium. Using (5), we can obtain the following expressions for the tariff levels:

$$
\begin{aligned}
t^{C U, 1} & =\frac{(H-c)\left(1+2 \widehat{\gamma}_{A}\right)}{\left(11-2 \widehat{\gamma}_{A}\right)} \\
t^{C U, 2} & =\frac{(H-c)\left(1+2 \widehat{\gamma}_{B}\right)}{\left(11-2 \widehat{\gamma}_{B}\right)}
\end{aligned}
$$

It is clear from (19) that the greater the share of profits received by the elected representatives, the higher the tariff applied on trade with non-members.

Turning now to the selection of the representative, the first order condition of problem 17 is given by

$$
\frac{\partial v\left(\mathbf{t}^{C U}\left(\widehat{\gamma}_{A}, \widehat{\gamma}_{B}\right), \gamma_{A}^{m}\right)}{\partial t^{C U, 1}} \frac{\partial t^{C U, 1}}{\partial \widehat{\gamma}_{A}}=0
$$

where we used $\frac{\partial t^{C U, 2}}{\partial \widehat{\gamma}_{A}}=0$ following (19). We know that $\frac{\partial t^{C U, 1}}{\partial \widehat{\gamma}_{A}} \neq 0$ using expression (19), which implies that equation (20) yields $\frac{\partial v}{\partial t^{C U, 1}}=0$. Substituting equilibrium conditions (5) into equation (20) yields the following:

$$
(H-c)\left(1+4 \gamma^{m}\right)-\left(11-4 \gamma^{m}\right) t^{C U, 1}=0
$$

Substituting $t^{C U, 1}$ from (19) we have that

$$
\widehat{\gamma}_{A}=2 \gamma^{m}
$$


The intuition for lemma 2 works as follows. In the case of customs unions, the benefits of implementing a tariff on imports of good 1 accrue to country $A$ while the costs of the tariff are equally shared between the member countries. However, cooperative tariff setting forces the representatives to internalize the negative externalities on country $B$ from a tariff imposed on imports of good 1. Anticipating this cooperative outcome, the median voter in country $A$ is better off by delegating power to a representative who is more protectionist than herself.

We can substitute the relationship in (22) into expression (19) to find the common external tariffs and obtain that

$$
\begin{aligned}
t^{C U, 1} & =\frac{(H-c)\left(4 \gamma^{m}+1\right)}{\left(11-4 \gamma^{m}\right)} \\
t^{C U, 2} & =\frac{(H-c)\left(4 \gamma^{m}+1\right)}{\left(11-4 \gamma^{m}\right)}
\end{aligned}
$$

In contrast to the other regimes we have considered so far, the tariff on the good not produced domestically in a CU also depends on the identity of a representative, namely the representative of the partner country. Note that both tariffs are increasing in $\gamma^{m}$, i.e. they decrease in the extent of inequality for similar reasons as before.

\subsection{Welfare Comparison}

In this section, we compare the welfare levels that can be achieved in the three possible trade policy scenarios we have considered. By comparing the right hand side of equations (14) and (23), it is clear that the common external tariffs under a customs union are higher than the external tariffs in an FTA, independently of the distribution of income, since they both depend on the median voter's share of economic profits. This result is well known, and has been obtained before for instance by Freund (2000) and Ornelas (2007). However, lemmas 1 and 2 indicate that the median voter strategically delegate power in the case of customs unions but does delegate power in the case of free trade areas. Since representatives seek to maximize their own interest when choosing external tariffs, this might lead to a 
change in overall welfare when moving from free trade areas to customs unions.

In constructing our welfare measure in both countries we weight equally the utility of all individuals, and thus use the average voter's indirect utility function, $v(\mathbf{t}, \bar{\gamma}) .{ }^{9}$ Using the external tariffs described by expressions (14) and (23), and applying equilibrium price and quantity described in expressions (5), we obtain the following welfare measures:

$$
\begin{gathered}
v\left(\mathbf{t}^{C U}, \bar{\gamma}_{A}=1\right)=\frac{(H-c)^{2}\left(87-40 \gamma^{m}-16 \gamma^{m^{2}}\right)}{\left(11-4 \gamma^{m}\right)^{2}}+\pi_{A, F}^{1} \\
v\left(\mathbf{t}^{F T A}, \bar{\gamma}_{A}=1\right)=\frac{(H-c)^{2}\left(10527-3124 \gamma^{m}-68 \gamma^{m^{2}}\right)}{121\left(11-2 \gamma^{m}\right)^{2}}+\pi_{A, F}^{1}
\end{gathered}
$$

where $\pi_{A, F}^{1}$ does not change since markets are segmented, and, therefore, equilibrium prices in country $F$ do not depend on the trade policy implemented by countries $A$ and $B$. The expressions (24) can be used to show that $v\left(\mathbf{t}^{F T A}, \bar{\gamma}_{A}\right)>v\left(\mathbf{t}^{C U}, \bar{\gamma}_{A}\right)$ if the difference between the fraction of profits received by the median voter and by the average voter is sufficiently small. In particular, we are able to show that

Proposition 1 Free trade areas raise member countries' welfare relative to customs unions as long as the fraction of profits received by the median voter $\gamma^{m} \in(0, \bar{\gamma}=1)$ exceeds a critical level $\tilde{\gamma}_{F T A, C U}^{m}$.

Proof. Note that $v\left(\mathbf{t}^{C U}, \bar{\gamma}_{A}\right)-v\left(\mathbf{t}^{F T A}, \bar{\gamma}_{A}\right)=-\frac{32(H-c)^{2} \gamma^{m}\left(208 \gamma^{m^{3}}-3432 \gamma^{m^{2}}+12947 \gamma^{m}-7986\right)}{121\left(8 \gamma^{m^{2}}-66 \gamma^{m}+121\right)^{2}}$. Assuming that $\gamma^{m}>0$, then the solution to $208 \gamma^{m^{3}}-3432 \gamma^{m^{2}}+12947 \gamma^{m}-7986=0$ indicates the value for $\gamma^{m}$ such that $v\left(\mathbf{t}^{C U}, \bar{\gamma}_{A}\right)=v\left(\mathbf{t}^{F T A}, \bar{\gamma}_{A}\right)$. It is easy to show that only one root is between zero and one: $\gamma^{m}=0.7646$ (see Appendix A for details of the calculations). Thus, for $0.7646=\tilde{\gamma}_{F T A, C U}^{m}<\gamma^{m}<1$ we have that $v\left(\mathbf{t}^{C U}, \bar{\gamma}_{A}\right)<v\left(\mathbf{t}^{F T A}, \bar{\gamma}_{A}\right)$. Otherwise, $v\left(\mathbf{t}^{C U}, \bar{\gamma}_{A}\right)>v\left(\mathbf{t}^{F T A}, \bar{\gamma}_{A}\right)$.

The intuition behind Proposition 1 is as follows. Equation (2) indicates that aggregate welfare can be described as the sum of factor income, tariff revenues and consumer surplus. Since common external tariffs are higher than external tariffs in an FTA, consumer surplus

\footnotetext{
${ }^{9}$ See also Facchini, Lorz and Willmann (2006).
} 
(profits) is lower (higher) in a customs union than in an FTA. In principle, the comparison of the sum of these two terms yields ambiguous results, but it can be shown (see Appendix $A$ ) that the sum of consumer surplus and profits is higher in customs unions than FTAs. Comparing tariff revenue to the sum of consumer surplus and profit is thus key to explaining Proposition 1: If the degree of inequality is low, that is $\gamma^{m} \in\left(\tilde{\gamma}_{F T A, C U}^{m}, 1\right)$, then the common external tariffs are high enough to lead to a substantially low level of imports from nonmembers. In this case, the tariff revenue in a customs union is sufficiently lower than in an FTA as to make member countries' welfare decrease when moving from an FTA to a CU.

Before investigating the political viability of FTAs and customs unions, it is important to understand the changes in welfare when moving from a regime where MFN tariffs are applied to a regime where a preferential trade agreement between $A$ and $B$ is in place. Using external tariffs described by expressions (12) in lemma 1 and applying equilibrium prices and quantities described in expressions (5) we obtain the following welfare measure:

$$
v\left(\mathbf{t}^{M F N}, \bar{\gamma}_{A}=1\right)=-\frac{(H-c)^{2}\left(-1301+380 \gamma^{m}+12 \gamma^{m^{2}}\right)}{16\left(11-2 \gamma^{m}\right)^{2}}
$$

We can use expressions (24) and (25) to establish the following result:

Proposition 2 The creation of a free trade area raises member countries' welfare relative to the MFN regime, regardless of the fraction of profits received by the median voter $\gamma^{m} \in$ $(0,1)$. Furthermore, if the share of profits received by the median voter exceeds a critical level $\tilde{\gamma}_{C U, M F N}^{m} \in\left(\tilde{\gamma}_{F T A, C U}^{m}, 1\right)$, then a customs union decreases member countries' welfare relative to the MFN regime. Finally, if $\gamma^{m} \in\left(\tilde{\gamma}_{F T A, C U}^{m}, \tilde{\gamma}_{C U, M F N}^{m}\right)$ then a customs union welfare dominates the MFN regime but is dominated by an FTA.

Proof. Notice that $v\left(\mathbf{t}^{F T A}, \bar{\gamma}_{A}\right)-v\left(\mathbf{t}^{M F N}, \bar{\gamma}_{A}\right)=\frac{91(H-c)^{2}}{1936}>0$. Thus, it is positive independently of the income distribution. The difference between $v\left(\mathbf{t}^{C U}, \bar{\gamma}_{A}\right)$ and $v\left(\mathbf{t}^{M F N}, \bar{\gamma}_{A}\right)$ equals $-\frac{(H-c)^{2}\left(-11011-21780 \gamma^{m}+50052 \gamma^{m^{2}}-13728 \gamma^{m^{3}}+832 \gamma^{m^{4}}\right)}{16\left(121-66 \gamma^{m}+8 \gamma^{m^{2}}\right)^{2}}$. The solution to $-11011-21780 \gamma^{m}+$ $50052 \gamma^{m^{2}}-13728 \gamma^{m^{3}}+832 \gamma^{m^{4}}=0$ indicates the value for $\gamma^{m}$ such that $v\left(\mathbf{t}^{C U}, \bar{\gamma}_{A}\right)=$ $v\left(\mathbf{t}^{M F N}, \bar{\gamma}_{A}\right)$. As discussed in Appendix $\mathrm{B}$, only one of the solutions is between zero and 
one: $\gamma^{m}=0.8874$. Thus, for $0.8874=\tilde{\gamma}_{C U, M F N}^{m}<\gamma^{m}<1$ we have that $v\left(\mathbf{t}^{C U}, \bar{\gamma}_{A}\right)<$ $v\left(\mathbf{t}^{M F N}, \bar{\gamma}_{A}\right)$. Otherwise, $v\left(\mathbf{t}^{C U}, \bar{\gamma}_{A}\right)>v\left(\mathbf{t}^{M F N}, \bar{\gamma}_{A}\right)$.

Continuing to use country $A$ 's point of view to explain our results, the welfare comparison between the FTA and the MFN regimes can be understood in the following way. Lemma 1 shows that country $A$ 's MFN tariff on good 1 is equal under both scenarios, and country $B$ does not produce good 1 . Thus, there are no welfare differences related to the consumption of good 1 in country $A$. The profits of the firm producing good 1 in country $A$ increase since it has preferential access to country B's market after the formation of the FTA. At the same time, country $A$ just relies on imports to meet its demand of good 2. Lemma 1 indicates that country $A$ 's MFN tariff on good 2 is higher than its tariff when an FTA is in place. Moreover, country $B$ 's firm has duty free access to country $A$ 's market when an FTA is in place. Then, it can be easily shown (see Appendix B) that the gains in consumer surplus obtained from the FTA formation are lower than the losses in tariff revenue. However, the profits increase of the firm that produces good 1 in country $A$ more than compensates for the welfare losses in the market for good 2. Thus, Proposition 2 shows that an FTA raises the welfare of member countries with respect to the MFN regime.

The analysis of changes in welfare due to the formation of customs unions follows along the lines of Proposition 1. The common external tariff applied on imports of good 1 is higher than the MFN tariff applied on imports of this good by country $A$. Thus, the price of good 1 is higher in country $A$ when a customs union is in place than under the MFN regime. In this case, one can show that the sum of consumer surplus and profits related to good 1 is higher when a customs union is in place. In the case of good 2, prices can be higher or lower depending on the degree of inequality. The sum of consumer surplus and profits across goods is positive, independently of the level of inequality. Then, changes in tariff revenue are again key to explain the result. If the degree of inequality is low, that is $\gamma^{m} \in\left(\hat{\gamma}_{C U, M F N}^{m}, 1\right)$, then the common external tariffs are sufficiently higher than MFN tariffs and lead to a substantial fall in the quantity imported from country $F$ compared to the MFN level. The latter generates a decrease in tariff revenues and in welfare, when member countries move from the status quo to a customs union. 


\section{First Stage: Political Viability of PTAs}

In this section, we focus on the first stage of our model to study the political economy of preferential trade agreements. Each member country holds a sequence of referenda to decide whether an FTA, a customs union or a non-discriminatory MFN regime should be implemented. We start by considering a referendum in which each country is called upon to choose between the MFN regime and the formation of an FTA. Once the outcome of this referendum is known, the polity is asked to choose between the result of the first referendum and a deeper form of integration, namely a Customs Union. ${ }^{10}$

If countries $A$ and $B$ decide to form a preferential agreement, then voters choose the representative that will decide trade tariffs as described in the previous section. Otherwise, the MFN trade policy remains in place. The set-up of the problem allows us to conclude that the median voter is pivotal in the referendum process.

Since the decision to form a preferential agreement is simultaneous, then an FTA (CU) is established if $\{F T A, F T A\}(\{C U, C U\})$ is a Nash equilibrium of this game. The possibility of choosing different preferential agreements may lead to an equilibrium that is not "politically efficient", i.e. a trade regime that is not the preferred regime according to median voters' preferences, but one that emerges as a political equilibrium due to the lack of coordination across countries over the choice of trade regime. To deal with this issue, let us first define the following concept:

Definition 1 A preferential trade agreement is politically viable if the median voter prefers it over the MFN regime.

Political viability of preferential agreements is measured using the median voter's indirect utility function, $v\left(\mathbf{t}, \gamma^{m}\right)$. We continue using the point of view of country $A$ to study the equilibrium of the game. A similar analysis applies to country $B$. Using external tariffs described by expressions (12), (14), and (23), and applying the equilibrium price and quantity

\footnotetext{
${ }^{10}$ Alternatively, we could start by considering the decision between the MFN arrangement and a CU and then, in the second stage, pit against each other the winner vs. an FTA. The two sequences deliver the same final outcome.
} 
described in expressions (5), we obtain the following measures:

$$
\begin{aligned}
v\left(\mathbf{t}^{C U}, \gamma_{A}^{m}\right) & =\frac{(H-c)^{2}\left(55-8 \gamma^{m}-16 \gamma^{m^{2}}\right)}{\left(11-4 \gamma^{m}\right)^{2}}+\gamma^{m} \pi_{A, F}^{1} \\
v\left(\mathbf{t}^{F T A}, \gamma_{A}^{m}\right) & =\frac{(H-c)^{2}\left(605+242 \gamma^{m}-32 \gamma^{m^{2}}\right)}{121\left(11-2 \gamma^{m}\right)}+\gamma^{m} \pi_{A, F}^{1} \\
v\left(\mathbf{t}^{M F N}, \gamma_{A}^{m}\right) & =\frac{(H-c)^{2}\left(84+19 \gamma^{m}-2 \gamma^{m^{2}}\right)}{176-32 \gamma^{m}}+\gamma^{m} \pi_{A, F}^{1}
\end{aligned}
$$

We are now ready to state our first result characterizing the conditions under which a free trade area will emerge as a political equilibrium.

Proposition 3 The formation of a free trade area will be preferred over the MFN regime if the share of profits received by the median voter $\gamma^{m} \in(0,1)$ exceeds a critical level $\breve{\gamma}_{F T A, M F N}^{m}$.

Proof. Comparing expressions (26) it can be shown that the difference between $v\left(\mathbf{t}^{F T A}, \gamma_{A}^{m}\right)$ and $v\left(\mathbf{t}^{M F N}, \gamma_{A}^{m}\right)$ equals $\frac{(H-c)^{2}\left(135 \gamma^{m}-44\right)}{1936}$. This implies that $v\left(\mathbf{t}^{F T A}, \gamma_{A}^{m}\right)>v\left(\mathbf{t}^{M F N}, \gamma_{A}^{m}\right)$ if $0.3259=\breve{\gamma}_{F T A, M F N}^{m}<\gamma^{m}<1$.

Proposition 3 says that an FTA is politically viable if the level of inequality is sufficiently small. What is the intuition behind this result? We can write the change in the median voter's indirect utility comparing the MFN regime to the formation of a PTA in the following manner:

$$
\Delta v\left(\mathbf{t}^{M F N}, \mathbf{t}^{P T A}, \gamma_{A}^{m}\right)=\underbrace{\Delta v\left(\mathbf{t}^{M F N}, \mathbf{t}^{P T A}, \bar{\gamma}_{A}\right)}_{\text {Social welfare }}-\underbrace{\left(1-\gamma_{A}^{m}\right)}_{\text {Inequality }}(\underbrace{\left(\Delta \pi_{A}^{1}\left(\mathbf{t}^{M F N}, \mathbf{t}^{P T A}\right)\right)}_{\text {Pr ofits }}
$$

where ' $\Delta$ ' represents the change in variables from the MFN regime to a preferential agreement and $\mathbf{t}^{M F N}, \mathbf{t}^{P T A}$ represent respectively the tariff matrixes in the MFN regime and when a preferential trading arrangement has been introduced. The second term on the righthand-side of expression (27) highlights the importance of profit changes when comparing the different trade regimes. Using the external tariffs described by expressions (12), (14) and (23), and applying equilibrium price and quantity described in expressions (5), allow us to 
obtain the following profit measures:

$$
\begin{aligned}
\pi_{A}^{1}\left(\mathbf{t}^{M F N}\right) & =\frac{(H-c)^{2}\left(377-44 \gamma^{m}+4 \gamma^{m^{2}}\right)}{16\left(11-2 \gamma^{m}\right)^{2}}+\pi_{A, F}^{1} \\
\pi_{A}^{1}\left(\mathbf{t}^{F T A}\right) & =\frac{32(H-c)^{2}\left(121-22 \gamma^{m}+2 \gamma^{m^{2}}\right)}{121\left(11-2 \gamma^{m}\right)^{2}}+\pi_{A, F}^{1} \\
\pi_{A}^{1}\left(\mathbf{t}^{C U}\right) & =\frac{32(H-c)^{2}}{\left(11-4 \gamma^{m}\right)^{2}}+\pi_{A, F}^{1}
\end{aligned}
$$

Equation (27) indicates that the median voter's indirect utility is positively correlated with changes in social welfare and negatively correlated to changes in the product of profits and inequality. Expression (27) makes clear that increases in profits relative to the MFN regime are not as important on political grounds as they are on welfare grounds since the median voter receives a share of profits which is lower than the average. Proposition 2 established that an FTA raises social welfare relative to the MFN regime. This implies that the first term on the right-hand-side of expression (27) is positive. Furthermore, we also know from proposition 2 that this term does not depend on the extent of inequality.

As for the second term, we know from the previous sections that an FTA raises profits relative to the MFN regime. Expressions (28) can be used to conclude that the increase in profits generated by the creation of an FTA relative to the MFN regime is equal to $\frac{135(H-c)^{2}}{1936}$. Thus, this increase does not depend on the extent of inequality. This is true since lemma 1 indicates that the MFN and FTA tariffs applied by country $A$ on good 1 are the same, and the tariffs applied by country $B$ on good 1 under the MFN and FTA regimes do not depend on the extent of inequality (see expressions (12) and (14)). Since the difference between the average and the median ownership share is also positive, the second term on the right-handside of equation (27) is positive. In this case, the product of the extent of inequality and change of profits, which corresponds to the second term on the right-hand-side of equation (27), decreases with $\gamma^{m}$. Taking into account the minus sign, and recalling that the first term does not vary with $\gamma^{m}$, the change in the median voter's indirect utility is thus increasing in $\gamma^{m}$, which establishes the result.

We are now in a position to consider the outcome of the vote between the MFN regime 
and the creation of a customs union. Our result in this case is summarized in the following

Proposition 4 A customs union will never win over the MFN regime.

Proof. Using expressions (26) it can be shown that $v\left(\mathbf{t}^{M F N}, \gamma_{A}^{m}\right) \geqslant v\left(\mathbf{t}^{C U}, \gamma_{A}^{m}\right)$ for any $\gamma^{m} \epsilon(0,1)$. The mathematical details of the proof can be found in Appendix C.

To understand the intuition behind this result, we can use once again the equivalent to equation (27) applied in the context of the MFN and customs union regimes. Recall that the common external tariffs under a customs union (see expressions (23)) are higher than the MFN tariffs (see expressions (12)). Then, profits are higher under a customs union than under the MFN regime, and, consequently, the second term on the right-hand-side of expression (27) is positive. Taking into account the minus sign in front of the second term on the right-hand-side of expression (27), we can conclude that the decrease in the importance of profit increases makes customs unions politically inviable.

In principle, the value of the median voter's indirect utility function could increase when moving from the MFN regime to a customs union if social welfare increased sufficiently to compensate for the negative effect created by the variation in profits. Proposition 2 shows that the latter happens if the level of inequality is sufficiently high, i.e. $\gamma^{m} \epsilon\left(0, \tilde{\gamma}_{C U, M F N}^{m}\right)$. However, the second term on the right-hand-side of expression (27) also depends on the level of inequality, and it can be shown that it may increase or decrease with changes in the level of inequality (see Appendix C). The net effect is that the absolute value of the second term on the right-hand-side exceeds the absolute value of the first term on the right-hand-side. This explains the result described in Proposition 4.

Last, we consider the possibility that a referendum is called - when a free trade area has been established - to deepen the extent of the integration and create a customs union. From proposition 3 and 4 and using transitivity, it follows immediately that

Proposition 5 A customs union will never be preferred over a free trade area.

From our analysis, we can thus conclude that only the formation of an FTA is a politically viable alternative to the MFN regime in our setting with representative democracy. 


\section{Extensions}

In this section, we consider two important extensions of our analysis. First, we focus on the effect of an increase in competition on the political viability of different trade policy arrangements by allowing the number of firms active in $F$ to be larger than one. Second, we study the consequences of asymmetries in income distribution between prospective member countries. While carrying out these exercises, we retain all other assumptions of the model.

\subsection{Change in the number of firms in country $F$}

Let $n_{F}>1$ be the number of firms in country $F$ producing goods 1 and 2 , while one firm produces good $1(2)$ in country $A(B)$. The equilibrium prices and quantities are then given by:

$$
\begin{aligned}
x_{A, A}^{1} & =\frac{\left(H+n_{F} t_{F, A}^{1}-c\right)}{n_{F}+2} \\
x_{F, A}^{1} & =\frac{\left(H-2 t_{F, A}^{1}-c\right)}{n_{F}+2} \\
p_{A}^{1} & =\frac{\left(H+n_{F} t_{F, A}^{1}+\left(n_{F}+1\right) c\right)}{n_{F}+2} \\
x_{B, A}^{2} & =\frac{\left(H+n_{F} t_{F, A}^{2}-\left(n_{F}+1\right) t_{B, A}^{2}-c\right)}{n_{F}+2} \\
x_{F, A}^{2} & =\frac{\left(H+t_{B, A}^{2}-2 t_{F, A}^{2}-c\right)}{n_{F}+2} \\
p_{A}^{2} & =\frac{\left(H+n_{F} t_{F, A}^{2}+t_{B, A}^{2}+\left(n_{F}+1\right) c\right)}{n_{F}+2}
\end{aligned}
$$

where $x_{F, A}^{i}$ represents the quantity of good $i$ produced by a firm located in country $F$ and consumed in country $A$. Similar expressions apply to country $B$, where the differences reside in the fact that country $B$ does not produce good 1 .

The solutions of the second and third stages of the model follow the same steps as in the previous sections. It is easy to show that the results described in lemma 1 continue to be valid since the representative of each country continues to be the median voter in the MFN and FTA regimes, $\widehat{\gamma}=\gamma^{m}$. Thus, the median voter does not delegate power in these two 
cases. Moreover, lemma 2 also applies in this case since we find the same level of strategic delegation in the formation of customs unions, $\widehat{\gamma}=2 \gamma^{m}$. This indicates that the level of strategic delegation does not vary with the number of firms in country $F$. The equilibrium tariffs in the three possible scenarios are thus given by:

$$
\begin{aligned}
t_{A}^{M F N, 1} & =\frac{(H-c)\left(1+2 \gamma^{m}\right)}{3 n_{F}-2 n_{F} \gamma^{m}+8} \\
t_{A}^{M F N, 2} & =\frac{(H-c)}{n_{F}+3} \\
t_{A}^{F T A, 1} & =\frac{(H-c)\left(1+2 \gamma^{m}\right)}{3 n_{F}-2 n_{F} \gamma^{m}+8} \\
t_{A}^{F T A, 2} & =\frac{(H-c)}{3 n_{F}+8} \\
t_{A}^{C U, 1}=t_{A}^{C U, 2} & =\frac{(H-c)\left(1+4 \gamma^{m}\right)}{3 n_{F}-4 n_{F} \gamma^{m}+8}
\end{aligned}
$$

Notice that MFN and FTA tariffs are negatively related to the number of firms in country $F$. In the case of customs unions, tariffs may instead increase or decrease with the number of firms in country $F$. It is easy to show that if the level of inequality is relatively low $\left(0.75<\gamma^{m}<1\right)$, then tariffs increase when the number of firms in country $F$ increases. Otherwise, tariffs decrease when the number of firms in country $F$ increases.

To gain some intuition for the relationship between tariffs under different trade regimes and the number of firms in country $F$ let us assume tariffs to be chosen to maximize social welfare. We can use expressions (30), (31), and (32) $)^{11}$ to conclude that under this hypothesis, there exists a negative relationship between tariffs and the number of firms in country $F$. Notice though that in our framework, the representative of each member country may not correspond to the average voter and as a result, tariffs may not be chosen based on social concerns.

In the MFN and FTA regimes, the fraction of profits received by the representative (median) voter is less than the fraction received by the average voter, since we have assumed

\footnotetext{
${ }^{11}$ In this case, the tariffs that maximize welfare in the MFN and FTA regimes can be found by replacing $\gamma^{m}=1$ in expressions (30) and (31). In the case of customs unions, we replace $2 \gamma^{m}=1$ in expression (32).
} 
that $\gamma^{m}<1$. Thus, increases in profits due to tariff increases are less important to the representative voter than to the average voter. This explains the negative relationship between tariffs and the number of firms in country $F$ in the MFN and FTA regimes. On the contrary, the representative voter in customs unions may receive a fraction of profits greater than the average voter. In this case, tariffs may increase or decrease depending on the fraction of profits received by the representative voters. An increase in the number of firms in country $F$ may increase the strategic gains provided by the common external tariffs, which may lead to an increase in the common external tariffs if the representative voters receive a fraction of profits significantly greater than the fraction received by the average voter $\left(0.75<\gamma^{m}<1\right) .{ }^{12}$

We continue measuring the welfare level in member countries using the average voter's indirect utility function, $v(\mathbf{t}, \bar{\gamma})$. Using external tariffs derived in expressions (31) and (32), and applying the equilibrium price and quantity obtained in expressions (29) we obtain the following result:

Proposition 6 Free trade areas raise member countries' welfare relative to customs unions as long as the fraction of profits received by the median voter $\gamma^{m} \epsilon(0,1)$ exceeds a critical level $\tilde{\gamma}_{F T A, C U}^{m}\left(n_{F}\right)$. As the number of firms in country $F$ increases, the lower is $\tilde{\gamma}_{F T A, C U}^{m}\left(n_{F}\right)$.

The proof of Proposition 6 follows along the lines of Proposition 1 and requires us to calculate the fraction of profits received by the median voter that sets $v\left(\mathbf{t}^{C U}, \bar{\gamma}_{A}\right)$ equal to $v\left(\mathbf{t}^{F T A}, \bar{\gamma}_{A}\right)$. The solution of this process yields the critical level $\tilde{\gamma}_{F T A, C U}^{m}\left(n_{F}\right)$. Three solutions emerge from this process but only one provides an answer compatible with $0<$ $\gamma^{m}<1$. We have illustrated the relationship between $\tilde{\gamma}_{F T A, C U}^{m}$ and $n_{F}$ in figure 2. The graph shows that as the number of firms in country $F$ becomes larger, values of $\gamma^{m}>0.59$ imply that an FTA raises welfare relative to a customs unions. Using Propositions 1 and 6, we can show that the critical value $\tilde{\gamma}_{F T A, C U}^{m}\left(n_{F}\right)$ needed to ensure that an FTA raises welfare relative to customs union satisfies $0.59<\tilde{\gamma}_{F T A, C U}^{m}<0.76$. This implies that an increase in the number of firms in the rest of the world tends to make it more likely for an FTA to welfare dominate a customs union in our model.

\footnotetext{
${ }^{12}$ Remember that in this case $\hat{\gamma}_{A}=2 \gamma_{m}$.
} 


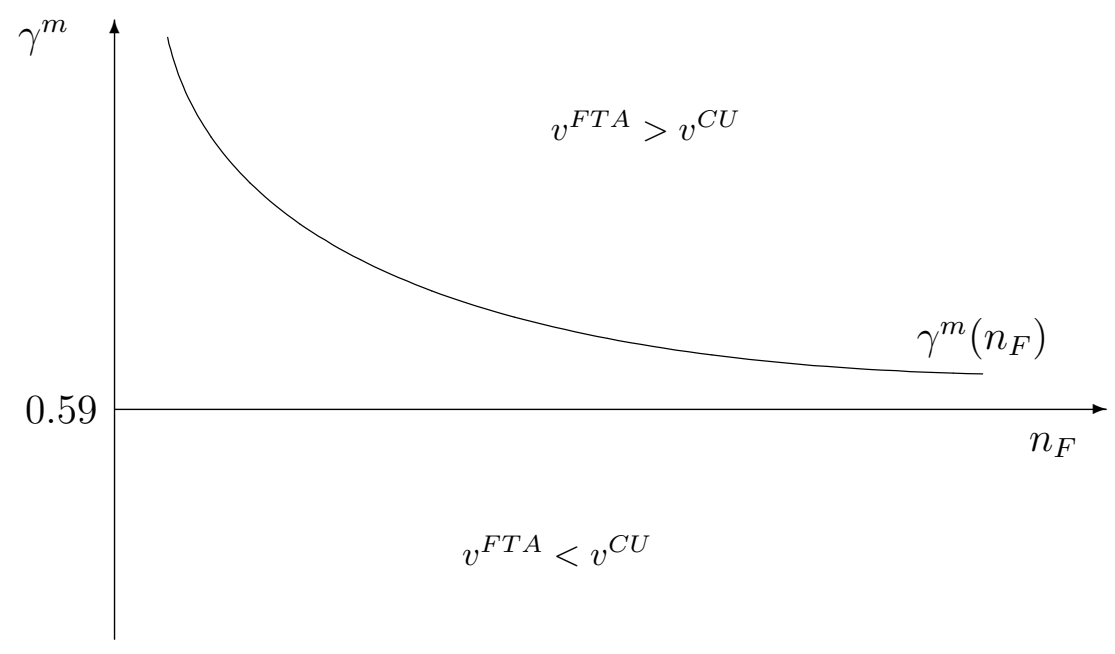

Figure 2: Increasing the number of firms in the rest of the world

It is also important to understand how average welfare changes when we compare the MFN regime with one in which a preferential trade agreement is in place between $A$ and $B$. We can conclude that:

Proposition 7 Free trade areas raise member countries' welfare relative to the MFN regime regardless of the fraction of profits received by the median voter $\gamma^{m} \epsilon(0,1)$. Furthermore, if the share of profits received by the median voter exceeds a critical level $\tilde{\gamma}_{C U, M F N}^{m}\left(n_{F}\right) \in$ $\left(\tilde{\gamma}_{F T A, C U}^{m}\left(n_{F}\right), 1\right)$, then a customs union decreases member countries' welfare relative to the $M F N$ regime. As the number of firms in country $F$ increases, the lower is $\tilde{\gamma}_{C U, M F N}^{m}\left(n_{F}\right)$.

The proof of Proposition 7 follows the same steps as the proof for Proposition 2. We can show that the difference between $v\left(\mathbf{t}^{F T A}, \bar{\gamma}_{A}\right)$ and $v\left(\mathbf{t}^{M F N}, \bar{\gamma}_{A}\right)$ is positive for $0<$ $\gamma^{m} \leqslant 1$. Thus, it is not dependent on the distribution of income. The difference between $v\left(\mathbf{t}^{C U}, \bar{\gamma}_{A}\right)$ and $v\left(\mathbf{t}^{M F N}, \bar{\gamma}_{A}\right)$ yields a complex expression but simulations ${ }^{13}$ indicate that as we increase the number of firms in country $F$, the lower is the critical value $\tilde{\gamma}_{C U, M F N}^{m}\left(n_{F}\right)$ so that $v\left(\mathbf{t}^{C U}, \bar{\gamma}_{A}\right)$ equals $v\left(\mathbf{t}^{M F N}, \bar{\gamma}_{A}\right)$ decreases. This exercise also indicates that as $n_{F}$ grows bigger, the minimum cutoff for $\gamma^{m}$ converges to 0.59 (and the picture would look very similar to Figure 1). In general, Propositions 6 and 7 indicate that as the number of firms

\footnotetext{
${ }^{13}$ The simulation exercise focuses on varying $n_{F}$ to calculate $\gamma^{m} \in(0,1]$ such that $v\left(\mathbf{t}^{C U}, \bar{\gamma}_{A}\right)=$ $v\left(\mathbf{t}^{M F N}, \bar{\gamma}_{A}\right)$.
} 
in country $F$ grows, so does the size of the parameter space guaranteeing that the FTA and the MFN regimes are preferred on welfare grounds to the formation of a customs union.

Learning about the welfare effects of the formation of preferential agreements is desirable but the implementation of preferential agreements depends on their political viability. As before, the median voter is pivotal in the sequence of referenda and thus the political viability of preferential agreements continues to be measured using the median voter's indirect utility function, $v\left(\mathbf{t}, \gamma^{m}\right)$. Focusing on country $A$ (the analysis for $B$ is similar), using external tariffs described by expressions (30), (31), and (32), and applying the equilibrium price and quantity obtained in expressions (29), we can establish the following

Proposition 8 The formation of a customs union is not politically viable. On the other hand, the formation of a free trade area will emerge as an equilibrium if the share of profits received by the median voter $\gamma^{m} \in(0,1)$ exceeds a critical value $\breve{\gamma}_{F T A, M F N}^{m}\left(n_{F}\right)$. As the number of firms in country $F$ increases, the higher is $\breve{\gamma}_{F T A, M F N}^{m}\left(n_{F}\right)$.

The proof of Proposition 8 follows the same steps as the proof of Propositions 3,4 and 5. Comparing the expressions for $v\left(\mathbf{t}^{C U}, \gamma_{A}^{m}\right)$ and $v\left(\mathbf{t}^{M F N}, \gamma_{A}^{m}\right)$, simulations ${ }^{14}$ indicate that there is no $\gamma^{m} \in(0,1]$ such that $v\left(\mathbf{t}^{C U}, \gamma_{A}^{m}\right)>v\left(\mathbf{t}^{M F N}, \gamma_{A}^{m}\right)$. The difference between $v\left(\mathbf{t}^{F T A}, \gamma_{A}^{m}\right)$ and $v\left(\mathbf{t}^{M F N}, \gamma_{A}^{m}\right)$ yields the expression $-24-17 n_{F}-3 n_{F}^{2}+\gamma_{A}^{m}\left(80+48 n_{F}+7 n_{F}\right)$. We can then set $v\left(\mathbf{t}^{F T A}, \gamma_{A}^{m}\right)$ equal to $v\left(\mathbf{t}^{M F N}, \gamma_{A}^{m}\right)$ to find $\breve{\gamma}_{F T A, M F N}^{m}\left(n_{F}\right)=\frac{\left(24+17 n_{F}+3 n_{F}^{2}\right)}{\left(80+48 n_{F}+7 n_{F}^{2}\right)}$. The latter expression can be used to show that as the number of firms in country $F$ increases, the higher is the critical value $\breve{\gamma}_{F T A, M F N}^{m}$ so that a free trade area will emerge as an equilibrium. In general, Propositions 5-10 extend the results from previous sections by highlighting once again the welfare desirability and political viability of FTA formation when the level of inequality is relatively low.

\subsection{Differences in income distribution}

In this section, we consider the effect of asymmetries in the income distribution between prospective member countries $\left(\gamma_{A}^{m} \neq \gamma_{B}^{m}\right)$ on the formation of preferential trading arrange-

\footnotetext{
${ }^{14}$ The simulation exercise focuses on varying $n_{F}$ to calculate $\gamma^{m}$ such that $v\left(\mathbf{t}^{C U}, \gamma_{A}^{m}\right)=v\left(\mathbf{t}^{M F N}, \gamma_{A}^{m}\right)$. In this case, we could not find $\gamma^{m} \in\{0,1]$ that satisfies that equality.
} 
ments. All other assumptions in the model are retained, and in particular that the number of firms in country $F$ is equal to one. Our starting point is the investigation of whether Propositions 1-2 continue to hold if $\gamma_{A}^{m} \neq \gamma_{B}^{m}$. For each member country, the analysis is carried out in three steps. First, we consider the equilibrium in the market for good 1, then the equilibrium in the market for good 2 , and finally exports to the partner country.

We will continue to take the point of view of country $A$. As seen before, country $A$ 's representative corresponds to the median voter in both the MFN and FTA regime, i.e. $\widehat{\gamma}_{A}=\gamma_{A}^{m}$. Thus, the median voter does not delegate power in these two cases. Moreover, if a customs unions is formed, strategic delegation occurs and $\widehat{\gamma}_{A}=2 \gamma_{A}^{m}$. Furthermore, the level of strategic delegation does not vary with the distribution of income in country $B$. These results imply that lemmas 1 and 2 remain valid in this context.

The equilibrium in the market for good 1 in country $A$ depends only on $\gamma_{A}^{m}$, whatever trade regime is in place as indicated by expressions (10), (13), and (19). This implies that in comparing trade regimes, the fact that $\gamma_{A}^{m} \neq \gamma_{B}^{m}$ plays no role as far as the equilibrium in the market for good 1 in country $A$ is concerned. Similarly, exports of good 1 from country $A$ to country $B$ do not depend on $\gamma_{B}^{m}$ as described by expressions (10), (13), and (19). Therefore, the differences in income inequality between the two countries play no role in this case as well.

The same is not true for the determination of the equilibrium in the market for good 2 in country $A$. In fact, from equation (19) we can see that, whenever a customs union is in place, the equilibrium price in that market depends on the distribution of income in country $B$. This has implications for the welfare comparison of a customs unions and an FTA and of a customs union and the MFN regime, which are summarized in the following

Proposition 9 Free trade areas raise member countries' welfare relative to the MFN regime for any member countries' income distribution. For relatively high inequality levels, the lower the share of profits received by the partner country's median voter, the lower the critical value $\tilde{\gamma}_{A, F T A, C U}^{m}\left(\tilde{\gamma}_{A, C U, M F N}^{m}\right)$ of the share of profits received by the country's median voter needed for a customs union to raise welfare relative to the free trade area (MFN) situation. For relatively low inequality levels, at least one of the member countries will be worse-off after 
the customs union formation.

The difference between $v\left(\mathbf{t}^{F T A}, \bar{\gamma}_{A}\right)$ and $v\left(\mathbf{t}^{M F N}, \bar{\gamma}_{A}\right)$ is the same one we calculated in the proof of Proposition 2, and the reasons for this results are described above. The differences between $v\left(\mathbf{t}^{C U}, \bar{\gamma}_{A}\right)$ and $v\left(\mathbf{t}^{F T A}, \bar{\gamma}_{A}\right)$, and between $v\left(\mathbf{t}^{C U}, \bar{\gamma}_{A}\right)$ and $v\left(\mathbf{t}^{M F N}, \bar{\gamma}_{A}\right)$ are complex expressions ${ }^{15}$ so we rely on simulations to obtain the other results described in Proposition 9. The expression resulting from the difference between $v\left(\mathbf{t}^{C U}, \bar{\gamma}_{A}\right)$ and $v\left(\mathbf{t}^{F T A}, \bar{\gamma}_{A}\right)$, indicates that given $\gamma_{B}^{m} \leqslant 0.76$ one can find a minimum $\gamma_{A}^{m} \in\left(0, \tilde{\gamma}_{A, F T A, C U}^{m}\right)$ $\leqslant 0.76$ so that both countries can gain from the formation of a customs union. If one of the member countries has substantially low income inequality levels $\left(\gamma^{m}>0.76\right)$, then the partner country will always be worse-off after the formation of a customs union. The requirement related to the minimum level of inequality needed to form welfare-enhancing customs unions $\left(\gamma^{m}<0.76\right)$ relates to the result from Propositions 1 and 2. As we have argued before, if the degree of inequality is very low then the external tariffs are high enough to generate significant losses of tariff revenue. This is key to explaining the result. A similar rationale applies to the analysis of the comparison between a customs union and the MFN regime. ${ }^{16}$

Turning to the political viability of preferential agreements, we need once again to focus on the median voter's indirect utility function, $v\left(\mathbf{t}, \gamma^{m}\right)$. Following the same argument developed to establish Propositions 3, 4 and 5, it is easy to show that the formation of free trade areas is politically viable if the degrees of inequality are not extremely high, and in particular $\gamma^{m}$ $\epsilon\left(\tilde{\gamma}_{A, F T A, M F N}^{m}=0.3259,1\right)$.

Similarly, we can determine the outcome of a referendum between the MFN and a custom union regime by comparing $v\left(\mathbf{t}^{C U}, \gamma^{m}\right)$ and $v\left(\mathbf{t}^{M F N}, \gamma^{m}\right)$. The resulting expression is complex but simulations indicate that for a given $\gamma_{B}^{m}$ it is necessary to have $\gamma_{B}^{m} \leq \gamma_{A}^{m}$ $\epsilon\left(\tilde{\gamma}_{A, C U, M F N}^{m}, 1\right)$ for the customs union to be politically viable in country $A$. However, as the same argument applies to country $B$, the customs union cannot emerge as a political

\footnotetext{
${ }^{15}$ In this case, simulations are carried out to calculate the minimum fraction of profits received by the country's median voter needed to raise welfare in that country when a customs union is formed, given the share of profits received by the partner country's median voter.

${ }^{16}$ In this case, a customs union can be welfare-enhancing for both members if the degrees of inequality are not substantially low, $\gamma^{m}<0.88$.
} 
equilibrium in this case.

Note that assuming that country $F$ 's economy is larger than countries $A$ and $B$ 's economies (as measured by the parameter $H$ in the demand function) does not change the results described in Propositions 1-5. This is true since the equilibrium quantities and prices do not change in countries $A$ and $B$, as can be seen in expressions (5), (30), (31), and (32).

\section{Conclusions}

In this paper, we have developed a representative democracy model of the formation of a preferential trading arrangement to provide a rationale for the greater popularity of free trade areas over customs unions. Most of the existing literature finds that, due to the presence of tariff coordination, customs unions tend to raise welfare relative to free trade areas in member countries. In this paper, we have shown that this does not need to be the case. In particular we have found that if inequality is sufficiently small, an FTA raises welfare relative to a customs union for the member countries. The intuition for this result is that if income inequality is small, then voters elect very protectionist representatives when a customs union is in place. The political process can then result in high common external tariffs, which may be deleterious to welfare in member countries relative to the formation of a free trade area. Our analysis thus highlights the importance of taking into account the ex-ante income distribution in each country when we want to investigate the welfare consequences of the formation of preferential trade arrangements.

We have also used our framework to study the political viability of free trade areas and customs unions, and we have shown that FTAs are politically more viable than customs unions. This is an important result, as it provides a new rationale for the relatively low frequency of $\mathrm{CU}$ around the world. Once again, the political viability of FTAs depends on the degree of income inequality. Our results suggests that FTAs are politically palatable if the degree of income inequality is sufficiently small. Moreover, the results indicate that only welfare enhancing preferential trade agreements are politically viable, because increases in profits derived from preferential access are not as important on political grounds as they are on welfare grounds. These findings are robust to changes in the market size of non-member 
countries and to differences in income inequality across member countries.

\section{Appendix}

\subsection{Appendix A}

In this appendix we proof proposition 1 in the main text of the paper. We can focus on country $A$ to explain the welfare comparison between the customs union and the FTA situations. Using external tariffs described by expressions (14) and (23), and applying equilibrium prices and quantities described in expressions (5), allow us to compare the welfare levels between these two trade regimes. The sum of the changes in consumer surplus and producer surplus when member countries move from an FTA to a customs union can be represented by the following expression:

$$
\Delta C S_{A}+\Delta\left(\pi_{A, A}^{1}+\pi_{A, B}^{1}\right)=\frac{8 \gamma^{m}\left(3993+7502 \gamma^{m}-2640 \gamma^{m^{2}}+160 \gamma^{m^{3}}\right)(c-H)^{2}}{121\left(121-66 \gamma^{m}+8 \gamma^{m^{2}}\right)^{2}}
$$

where $\Delta C S_{A}$ represents the change in country $A$ 's consumer surplus. Expression (33) indicates that comparison of the sum of these terms is equal to zero if $3993+7502 \gamma^{m}-$ $2640 \gamma^{m^{2}}+160 \gamma^{m^{3}}$ equals zero. The values of $\gamma^{m}$ such that $3993+7502 \gamma^{m}-2640 \gamma^{m^{2}}+160 \gamma^{m^{3}}$ equals zero are $-0.45,4.32$, and 12.63. Since $\gamma^{m} \epsilon(0,1]$ then $\Delta C S+\Delta\left(\pi_{A, A}^{1}+\pi_{A, B}^{1}\right)$ is greater than zero in the parameter space under investigation.

The change in tariff revenue when member countries move from an FTA to a customs union is described by the following expression:

$$
\Delta T R_{A}=\frac{8 \gamma^{m}\left(-27951+59290 \gamma^{m}-16368 \gamma^{m^{2}}+992 \gamma^{m^{3}}\right)(c-H)^{2}}{121\left(121-66 \gamma^{m}+8 \gamma^{m^{2}}\right)^{2}}
$$

where $\Delta T R_{A}$ represents the change in country $A$ 's tariff revenue. Expression (34) indicates that the tariff revenue does not change between FTAs and customs unions if $-27951+59290 \gamma^{m}-16368 \gamma^{m^{2}}+992 \gamma^{m^{3}}$ equals zero. The values of $\gamma^{m}$ such that this expression equals zero are $0.55,4.41$, and 11.52. Thus, we can show that if $\gamma^{m}>(<) 0.55$ then tariff revenue in FTAs is greater (less) than in customs unions. In particular, if $\gamma^{m} \epsilon$ 
$(0.76,1]$ then $\Delta T R_{A}$ is sufficiently negative to generate the result that FTAs raise welfare relative to customs unions as described in Proposition 1.

\subsection{Appendix B}

In this appendix we prove proposition 2. Let us start by comparing welfare levels under the MFN and FTA regimes for country $A$ (the analysis for country $B$ is analogous). Using the external tariffs described by expressions (12) and (14), and applying equilibrium prices and quantities described in expressions (5), allow us to compare the welfare levels between these two trade regimes. As explained in the main body of the paper, there are no welfare differences related to the consumption of good 1 in country $A$. The increase in the profits of the firm that produces good 1 in country $A$ due the formation of the FTA equals $\frac{135(c-H)^{2}}{1936}$, which can be calculated using expressions (28). In the case of good 2 , the sum of the gains in consumer surplus and the losses in tariff revenue with the FTA formation equals $-\frac{(c-H)^{2}}{44}$. The summation of changes in profits, consumer surplus and tariff revenue equals $\frac{91(c-H)^{2}}{1936}$ as indicated in the proof of Proposition 2. Thus, Proposition 2 shows that an FTA raises the welfare of member countries with respect to the MFN regime.

Let us turn now to the welfare comparison between the MFN and customs union regimes. The sum of the changes in consumer surplus and producer surplus between the MFN and the customs union regimes can be represented by the following expression:

$$
\Delta C S_{A}+\Delta\left(\pi_{A, A}^{1}+\pi_{A, B}^{1}\right)=\frac{\left(34485-33396 \gamma^{m}+22756 \gamma^{m^{2}}-5280 \gamma^{m^{3}}+320 \gamma^{m^{4}}\right)(c-H)^{2}}{16\left(121-66 \gamma^{m}+8 \gamma^{m^{2}}\right)^{2}}
$$

where $\Delta C S_{A}$ represents the change in country $A$ 's consumer surplus. Expression (35) indicates that comparison of the sum of these terms is equal to zero if $34485-33396 \gamma^{m}+$ $22756 \gamma^{m^{2}}-5280 \gamma^{m^{3}}+320 \gamma^{m^{4}}$ equals zero. The real values of $\gamma^{m}$ such that $34485-$ $33396 \gamma^{m}+22756 \gamma^{m^{2}}-5280 \gamma^{m^{3}}+320 \gamma^{m^{4}}$ equals zero are 4.34 and 10.65 . Since $\gamma^{m} \epsilon(0,1]$ then $\Delta C S+\Delta\left(\pi_{A, A}^{1}+\pi_{A, B}^{1}\right)$ is greater than zero in the parameter space under investigation. 
The corresponding change in tariff revenue is given by:

$$
\Delta T R_{A}=-\frac{\left(11737-27588 \gamma^{m}+36404 \gamma^{m^{2}}-9504 \gamma^{m^{3}}+576 \gamma^{m^{4}}\right)(c-H)^{2}}{8\left(121-66 \gamma^{m}+8 \gamma^{m^{2}}\right)^{2}}
$$

where $\Delta T R_{A}$ represents the change in country $A$ 's tariff revenue. Expression (36) indicates that the tariff revenue does not change between the status quo and customs unions if $11737-$ $27588 \gamma^{m}+36404 \gamma^{m^{2}}-9504 \gamma^{m^{3}}+576 \gamma^{m^{4}}$ equals zero. There are no values of $\gamma^{m} \epsilon(0,1]$ such that this expression equals zero. This finding differs from the discussion on Appendix $A$ about the effects of customs union formation on tariff revenue, since tariffs in the MFN regime are non-discriminatory. Thus, moving from the MFN to a custom union regime is more costly in terms of tariff revenue than moving from an FTA to a customs union. We can then add expressions (35) and (36) to obtain the result described in Proposition 2.

\subsection{Appendix C}

In this appendix, we prove proposition 4. Focusing on country A, we can use expressions (5), (12), and (23) to calculate the increase in the profit of the firm that produces good 1 in country A when countries $A$ and $B$ move from the MFN to a customs union regime. This allows us to obtain the following expression for the second term on the right-hand-side of expression (27):

$$
\left(1-\gamma_{A}^{m}\right) \Delta \pi_{A}^{1}(\mathbf{t})=-\frac{\left(1-\gamma_{A}^{m}\right)\left(-16335-15972 \gamma^{m}+8340 \gamma^{m^{2}}-1056 \gamma^{m^{3}}+64 \gamma^{m^{4}}\right)(c-H)^{2}}{16\left(121-66 \gamma^{m}+8 \gamma^{m^{2}}\right)^{2}}
$$

It is easy to see using a graph that changes in inequality may increase or decrease the value of expression (37). Consider the case where $c-H$ equals 1 . The choice of parameters $c$ and $H$ is immaterial to the problem at hand. Figure 3 shows that expression (37) is (as expected) always positive and that it can increase or decrease with variations in income inequality.

We can calculate the value of expression (27) when country $A$ moves from the MFN to 


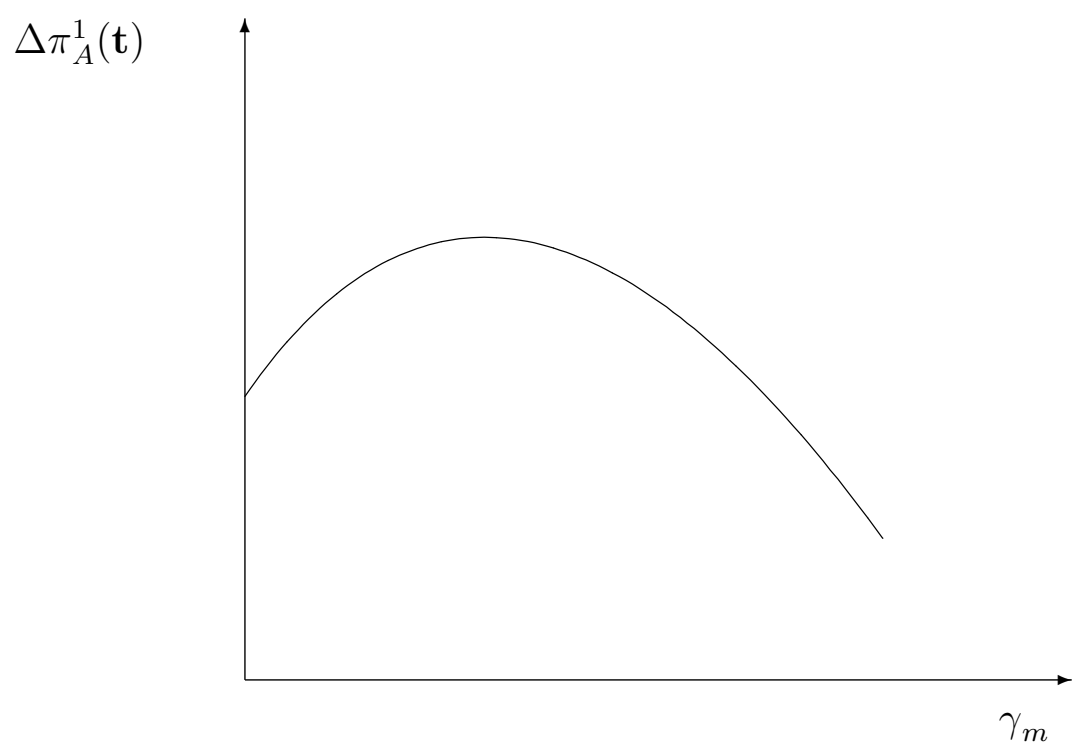

Figure 3: Varying the extent of income inequality

a customs union regime using expression (37), and using the value of the welfare change for that country which can be found in the proof of Proposition (2). The resulting expression can be described as follows:

$$
\Delta v\left(\mathbf{t}^{M F N}, \mathbf{t}^{C U}, \gamma_{A}^{m}\right)=-\frac{(H-c)^{2}\left(-484+1925 \gamma^{m}-1990 \gamma^{m^{2}}+32 \gamma^{m^{3}}+32 \gamma^{m^{4}}\right)}{16\left(121-66 \gamma^{m}+8 \gamma^{m^{2}}\right)^{2}}
$$

The solution of $-484+1925 \gamma^{m}-1990 \gamma^{m^{2}}+32 \gamma^{m^{3}}+32 \gamma^{m^{4}}=0$ indicates the value for $\gamma^{m}$ such that $v\left(\mathbf{t}^{M F N}, \gamma_{A}^{m}\right)=v\left(\mathbf{t}^{C U}, \gamma_{A}^{m}\right)$. None of the solutions are between zero and one. Thus, Proposition (4) concludes that customs unions will never be preferred over the MFN regime.

\section{References}

[1] Alesina, Alberto and Dani Rodrik (1994) "Distributive Politics and Economic Growth", Quarterly Journal of Economics, vol. 109, pp. 465-90 
[2] Conconi, Paola, Giovanni Facchini and Maurizio Zanardi (2008) "Fast Track Authority and International Trade Negotiations" CEPR WP 6790.

[3] Dutt, Pushan and Devashish Mitra (2002) "Endogenous Trade Policy Through Majority Voting: An Empirical Investigation," Journal of International Economics, vol. 58, pp. 107-134.

[4] Estevadeordal, Antoni, Caroline Freund and Emanuel Ornelas (2008) "Does regionalism affect trade liberalization towards non-members?" Quarterly Journal of Economics, forthcoming.

[5] Facchini, Giovanni and Cecilia Testa (2008) "Who is Against a Common Market?", Journal of the European Economic Association, forthcoming.

[6] Facchini, Giovanni, Oliver Lorz and Gerald Willmann (2006) "Asylum seekers in Europe: The warm glow of a hot potato" Journal of Population Economics, vol.19, pp. 411-430

[7] Freund, Caroline (2000) "Multilateralism and the endogenous formation of preferential trade agreements", Journal of International Economics, vol. 52, pp. 359-376.

[8] Gatsios, Konstantine and Larry Karp (1991) "Delegation games in customs unions" Review of Economic Studies 58: 391-397

[9] Grossman, Gene and Elhanan Helpman (1995) "The Politics of Free-Trade Agreements", American Economic Review, vol. 85, pp. 667-690.

[10] Grossman, Gene and Elhanan Helpman (2005) "A Protectionist Bias in Majoritarian Politics", Quarterly Journal of Economics, vol. 120, pp. 1239-1282.

[11] Helpman, Elhanan (1997) "Politics and Trade Policy", Advances in Economics and Econometrics: Theory and Applications, edited by David Kreps and Kenneth Wallis.

[12] Jones, Stephen R. G. (1989) "Have your lawyer call my lawyer: Bilateral delegation in bargaining situations" Journal of Economic Behavior and Organization, vol. 11, pp. 159-174 
[13] Krishna, Pravin (1998) "Regionalism and Multilateralism: A Political Economy Approach", Quarterly Journal of Economics, vol. 113, pp. 227-250.

[14] Laussel, Didier and Raymond Riezman (2005) "The sources of protectionist drift in representative democracies", European Economic Review, vol. 49, pp. 1855-1876.

[15] Ornelas, Emanuel (2005a) "Rent Destruction and the Political Viability of Free Trade Agreements", Quarterly Journal of Economics, vol. 120, pp. 1475-1506.

[16] Ornelas, Emanuel (2005b) "Trade Creating Free Trade Areas and the Undermining of Multilateralism", European Economic Review, vol. 49, pp. 1717-1735.

[17] Ornelas, Emanuel (2007) "Exchanging Market Access at the Outsiders' Expense - the Case of Customs Unions", Canadian Journal of Economics, vol. 40, pp. 207-224.

[18] Saggi, Kamal (2006) "Preferential Trade Agreements and Multilateral Tariff Cooperation," International Economic Review, vol. 47, pp. 29-57.

[19] Schelling, Thomas C. (1956) "An Essay on Bargaining" American Economic Review, vol. 46 , pp. $281-306$

[20] Segendorff, Berthold (1998) "Delegation and Threat in Bargaining" Games and Economic Behavior, vol. 23, pp. 266-283

[21] Willmann, Gerald (2005) "Why Legislators are Protectionists: The Role of Majoritarian Voting in Setting Tariffs", Kiel Working Paper 2003-10, University of Kiel. 


\section{CESifo Working Paper Series}

for full list see www.cesifo-group.org/wp

(address: Poschingerstr. 5, 81679 Munich, Germany, office@cesifo.de)

2365 Stefan Voigt, The (Economic) Effects of Lay Participation in Courts - A Cross-Country Analysis, August 2008

2366 Tobias König and Andreas Wagener, (Post-)Materialist Attitudes and the Mix of Capital and Labour Taxation, August 2008

2367 Ximing Wu, Andreas Savvides and Thanasis Stengos, The Global Joint Distribution of Income and Health, August 2008

2368 Alejandro Donado and Klaus Wälde, Trade Unions Go Global!, August 2008

2369 Hans Gersbach and Hans Haller, Exit and Power in General Equilibrium, August 2008

2370 Jan P.A.M. Jacobs and Jan-Egbert Sturm, The Information Content of KOF Indicators on Swiss Current Account Data Revisions, August 2008

2371 Oliver Hülsewig, Johannes Mayr and Timo Wollmershäuser, Forecasting Euro Area Real GDP: Optimal Pooling of Information, August 2008

2372 Tigran Poghosyan and Jakob de Haan, Determinants of Cross-Border Bank Acquisitions in Transition Economies: A Latent Class Analysis, August 2008

2373 David Anthoff and Richard S.J. Tol, On International Equity Weights and National Decision Making on Climate Change, August 2008

2374 Florian Englmaier and Arno Schmöller, Reserve Price Formation in Online Auctions, August 2008

2375 Karl Farmer, Birgit Friedl and Andreas Rainer, Effects of Unilateral Climate Policy on Terms of Trade, Capital Accumulation, and Welfare in a World Economy, August 2008

2376 Monika Bütler, Stefan Staubli and Maria Grazia Zito, The Role of the Annuity's Value on the Decision (Not) to Annuitize: Evidence from a Large Policy Change, August 2008

2377 Inmaculada Martínez-Zarzoso, The Impact of Urbanization on $\mathrm{CO}_{2}$ Emissions: Evidence from Developing Countries, August 2008

2378 Brian Roberson and Dmitriy Kvasov, The Non-Constant-Sum Colonel Blotto Game, August 2008

2379 Ian Dew-Becker, How Much Sunlight Does it Take to Disinfect a Boardroom? A Short History of Executive Compensation Regulation, August 2008

2380 Cécile Aubert, Oliver Falck and Stephan Heblich, Subsidizing National Champions: An Evolutionary Perspective, August 2008 
2381 Sebastian Buhai, Miguel Portela, Coen Teulings and Aico van Vuuren, Returns to Tenure or Seniority?, August 2008

2382 Erkki Koskela and Jan König, Flexible Outsourcing, Profit Sharing and Equilibrium Unemployment, August 2008

2383 Torberg Falch and Justina AV Fischer, Does a Generous Welfare State Crowd out Student Achievement? Panel Data Evidence from International Student Tests, September 2008

2384 Pedro Gomes and François Pouget, Corporate Tax Competition and the Decline of Public Investment, September 2008

2385 Marko Koethenbuerger, How Do Local Governments Decide on Public Policy in Fiscal Federalism? Tax vs. Expenditure Optimization, September 2008

2386 Ronald McKinnon and Gunther Schnabl, China's Exchange Rate Impasse and the Weak U.S. Dollar, September 2008

2387 Yan-Leung Cheung, Yin-Wong Cheung and Alan T.K. Wan, A High-Low Model of Daily Stock Price Ranges, September 2008

2388 Louis Eeckhoudt and Harris Schlesinger, Changes in Risk and the Demand for Saving, September 2008

2389 Carsten Hefeker and Blandine Zimmer, Uncertainty and Fiscal Policy in an Asymmetric Monetary Union, September 2008

2390 Jay Pil Choi and Byung-Cheol Kim, Net Neutrality and Investment Incentives, September 2008

2391 Marcel Gérard, Financing Bologna, the Internationally Mobile Students in European Higher Education, September 2008

2392 Annette Alstadsæter and Knut Reidar Wangen, Corporations' Choice of Tax Regime when Transition Costs are Small and Income Shifting Potential is Large, September 2008

2393 António Afonso and Christophe Rault, 3-Step Analysis of Public Finances Sustainability: the Case of the European Union, September 2008

2394 Betsey Stevenson and Justin Wolfers, Economic Growth and Subjective Well-Being: Reassessing the Easterlin Paradox, September 2008

2395 Bernhard Eckwert and Itzhak Zilcha, Private Investment in Higher Education: Comparing Alternative Funding Schemes, September 2008

2396 Øystein Foros, Hans Jarle Kind and Jan Yngve Sand, Slotting Allowances and Manufacturers' Retail Sales Effort, September 2008 
2397 Mohammad Reza Farzanegan, Illegal Trade in the Iranian Economy: Evidence from a Structural Model, September 2008

2398 Olivier Bos, Charity Auctions for the Happy Few, September 2008

2399 Robert S. Chirinko and Debdulal Mallick, The Marginal Product of Capital: A Persistent International Puzzle, September 2008

2400 Ben D'Exelle and Arno Riedl, Elite Capture, Political Voice and Exclusion from Aid: An Experimental Study, September 2008

2401 Torben M. Andersen and Joydeep Bhattacharya, On Myopia as Rationale for Social Security, September 2008

2402 Fabienne Llense, French CEO Compensations: What is the Cost of a Mandatory Upper Limit?, September 2008

2403 Valentina Bosetti, Carlo Carraro, Alessandra Sgobbi and Massimo Tavoni, Delayed Action and Uncertain Targets. How Much Will Climate Policy Cost?, September 2008

2404 Robert G. Chambers, Rolf Färe, Shawna Grosskopf and Michael Vardanyan, Generalized Quadratic Revenue Functions, September 2008

2405 Leonidas Enrique de la Rosa, Overconfidence in a Career-Concerns Setting, September 2008

2406 Marcus Drometer and Johannes Rincke, The Design of Political Institutions: Electoral Competition and the Choice of Ballot Access Restrictions in the United States, September 2008

2407 Markku Lanne and Helmut Lütkepohl, Stock Prices and Economic Fluctuations: A Markov Switching Structural Vector Autoregressive Analysis, September 2008

2408 Thomas L. Brewer, International Energy Technology Transfers for Climate Change Mitigations, September 2008

2409 Alexander Kemnitz, Native Welfare Losses from High Skilled Immigration, September 2008

2410 Xavier Vives, Strategic Supply Function Competition with Private Information, September 2008

2411 Fabio Padovano and Roberto Ricciuti, The Political Competition-Economic Performance Puzzle: Evidence from the OECD Countries and the Italian Regions, September 2008

2412 Joan Costa-Font and Mireia Jofre-Bonet, Body Image and Food Disorders: Evidence from a Sample of European Women, September 2008

2413 Thorsten Upmann, Labour Unions - To Unite or to Separate?, October 2008 
2414 Sascha O. Becker and Ludger Woessmann, Luther and the Girls: Religious Denomination and the Female Education Gap in $19^{\text {th }}$ Century Prussia, October 2008

2415 Florian Englmaier and Stephen Leider, Contractual and Organizational Structure with Reciprocal Agents, October 2008

2416 Vittorio Daniele and Ugo Marani, Organized Crime and Foreign Direct Investment: The Italian Case, October 2008

2417 Valentina Bosetti, Carlo Carraro, Alessandra Sgobbi and Massimo Tavoni, Modelling Economic Impacts of Alternative International Climate Policy Architectures. A Quantitative and Comparative Assessment of Architectures for Agreement, October 2008

2418 Paul De Grauwe, Animal Spirits and Monetary Policy, October 2008

2419 Guglielmo Maria Caporale, Christophe Rault, Robert Sova and Anamaria Sova, On the Bilateral Trade Effects of Free Trade Agreements between the EU-15 and the CEEC-4 Countries, October 2008

2420 Yin-Wong Cheung and Daniel Friedman, Speculative Attacks: A Laboratory Study in Continuous Time, October 2008

2421 Kamila Fialová and Ondřej Schneider, Labour Market Institutions and their Effect on Labour Market Performance in the New EU Member Countries, October 2008

2422 Alexander Ludwig and Michael Reiter, Sharing Demographic Risk - Who is Afraid of the Baby Bust?, October 2008

2423 Doina Maria Radulescu and Michael Stimmelmayr, The Welfare Loss from Differential Taxation of Sectors in Germany, October 2008

2424 Nikolaus Wolf, Was Germany ever United? Evidence from Intra- and International Trade 1885 - 1933, October 2008

2425 Bruno S. Frey, David A. Savage and Benno Torgler, Noblesse Oblige? Determinants of Survival in a Life and Death Situation, October 2008

2426 Giovanni Facchini, Peri Silva and Gerald Willmann, The Customs Union Issue: Why do we Observe so few of them?, October 2008 